\title{
Dates as data revisited: A statistical examination of the Peruvian Preceramic radiocarbon record
}

\section{Abstract}

This paper adopts a formal model-testing approach to the Peruvian radiocarbon $\left({ }^{14} \mathrm{C}\right)$ record, the site of the first aggregate analysis of this type of archaeological data. Using a large and improved regional dataset of radiometric determinations $(n=1180)$ from the period $14000-3000{ }^{14} \mathrm{C}$ years before present, the study performs a comparative analysis of the demographic trajectories of two subregions, the desert coast and Andean highlands. Against the backdrop of theoretical models of population growth, and controlling for taphonomic factors and sampling biases, the study performs global significance and permutation tests on the data. These provide a necessary measure of statistical confidence that have hereto been absent from the discussion of pre-Columbian demography. Contrary to the findings of prior work, this study of radiocarbon data in Peru reveals that regional trends in the data are statistically indistinguishable. Further testing and comparison to climate archives is able to illustrate sustained population growth over the entire Holocene epoch in this region, with only a few notable exceptions at the end of the mid-Holocene (5000 cal BP). The findings of the analysis are viewed in relation to the cultural and technological changes that indigenous societies experienced in the timeframe in question, and some directions for methodological advances are suggested. 


\section{Introduction}

More than three decades have passed since the publication of John Rick's seminal paper on the preceramic radiocarbon $\left({ }^{14} \mathrm{C}\right)$ record of coastal and highland Peru (Rick 1987). This work marks a watershed moment in model-based archaeology, as the principles defined in this paper went on to inspire a wealth of developments on the quantitative analysis of radiocarbon dates (Gamble et al. 2005; Surovell and Brantingham 2007; Williams 2012; Weninger et al. 2015). Most significant among these developments are robust statistical frameworks for assessing spatiotemporal trends in large ${ }^{14} \mathrm{C}$ datasets (Shennan et al 2013; Timpson et al. 2014; Crema et al. 2016; Palmisano et al. 2017; Crema et al. 2017; Edinborough et al. 2017; Bronk Ramsey 2017). Model-testing approaches such as these represent a significant advance on "eyeballing" peaks and troughs in the summed probability distributions of calibrated radiocarbon dates (hereafter SPDs), which until relatively recently have remained the norm. The advance of time has also brought improvements in atmospheric and marine calibration curves (Reimer et al. 2013; Hogg et al. 2013), as well as an expansion in the quantity of available ${ }^{14} \mathrm{C}$ dates in the published literature. This paper aims to re-evaluate the themes explored in the Peruvian ${ }^{14} \mathrm{C}$ record (Rick 1987), by capitalising on these methodological advances.

Previous findings based on the aggregation of radiocarbon data (Rick 1987) imply that the societies of the preceramic period in what is today Peru experienced divergent regional population histories from initial colonisation until the rise of complex aceramic polities around $3000 \mathrm{cal}$ BP. To summarise the specifics, this study argued that the coast and highlands had significantly different resource bases to draw from, and consequently derived an expectation of different demographic trajectories. While accounting for time-dependent loss of sites and regional sampling biases, the observed distributions of ${ }^{14} \mathrm{C}$ dates implied continuous exponential growth in the Coastal region, while in the Highlands a ceiling was quickly reached whereupon population stabilised around a mean, in the manner of a logistic curve. Although principally a methodological exercise, Rick's Dates as Data paper (1987) helped to confirm the precocious nature of desert coast population expansions and set the scene for subsequent developments in the aggregate analysis of radiocarbon data (Williams 2012; Timpson et al. 2014; Bronk Ramsey 2017). In the process, this added a novel perspective on demography to the quiver of archaeologists studying the rise of complex pre-Columbian societies as rooted in maritime adaptations (Quilter and Stocker 1983; Moseley 1992; Haas and Creamer 2006; Pozorski and Pozorski 2008). Due to the importance of this study for our understanding of pre-Columbian population fluctuation over a long span of time, the benefits of more advanced methods, as well as more expansive radiocarbon and comparative datasets can help further explore the issues raised and the trends identified in the original study. 
The period investigated in Dates as Data (13000 - $3000{ }^{14} \mathrm{C}$ years BP) saw several important developments among indigenous South American cultures. Among these is the transition from economies reliant on wild and intensively managed resources, towards an ever-increasing proportion and variety of cultigens in dietary profiles, as plants were domesticated and spread throughout South America (Pearsall 2008; Piperno 2011). Furthermore, physical adaptations to high altitude environments may have been necessary (Aldenderfer 2006). Several significant climatic fluctuations also took place in parallel to major cultural and technological transitions over this period, in particular the end of the Pleistocene (11700 cal BP), the Mid-Holocene phase (8200 to $4200 \mathrm{cal} \mathrm{BP}$ ), and the intensification of the El Niño Southern Oscillation (ENSO) as the Holocene progressed (Thompson et al. 2000; Moy et al. 2002; Walker et al. 2012). Intuitively, colonising groups inhabiting the range of biomes between the coastal strip and the highlands would have been required, over time, to deploy a similarly diverse set of strategies in the face of a potentially rapidly changing world (Aldenderfer 1999; Sandweiss 2003; Sandweiss et al. 2007). By the end of the preceramic period, complex and semisedentary societies are evident from the settlement, monumental, and bioarchaeological records (Shady Solis et al. 2001; Haas et al. 2004; Pozorski and Pozorski 2008; 2017). This wealth of new data available to archaeologists and the explicit references to population growth models by Rick (1987) provide useful starting points for the following investigation. The propositions of this model, in particular the identification of distinct demographic trends at different altitudes, provides a useful starting point for correlations between environment and long-term change in demography, which this study aims to test and compare directly. Nonetheless, the evidence for human presence in the desert coast and Andes before circa 14000 calendar years before present (cal BP) is contentious and sparse (Aldenderfer 2006; Rademaker et al. 2013; cf. Dillehay et al. 2015). This study focuses on preColumbian demography for the period $14000-3000 \mathrm{cal} B P$, after which the available archaeological evidence for human presence is on much stronger footing.

\section{Materials and methods}

The dataset employed here is composed of $1180{ }^{14} \mathrm{C}$ dates (Figure 1), compiled from published articles and compendiums (see particularly Rademaker et al. 2013; Goldberg et al. 2016). While unlikely to be exhaustive, represent at least a majority of the preceramic archaeological radiometric determinations in Peruvian territory. As a standard hygiene protocol (Shennan et al. 2013; Crema et al. 2016), 96 dates with standard errors $> \pm 200$ years have been excluded. In the analyses, dates are calibrated using the latest southern hemisphere calibration curve (Hogg et al. 2013), except for determinations on marine shell and human remains ( $n=138,11.7 \%$ of the dataset), which use the offset Marine13 curve (Reimer 

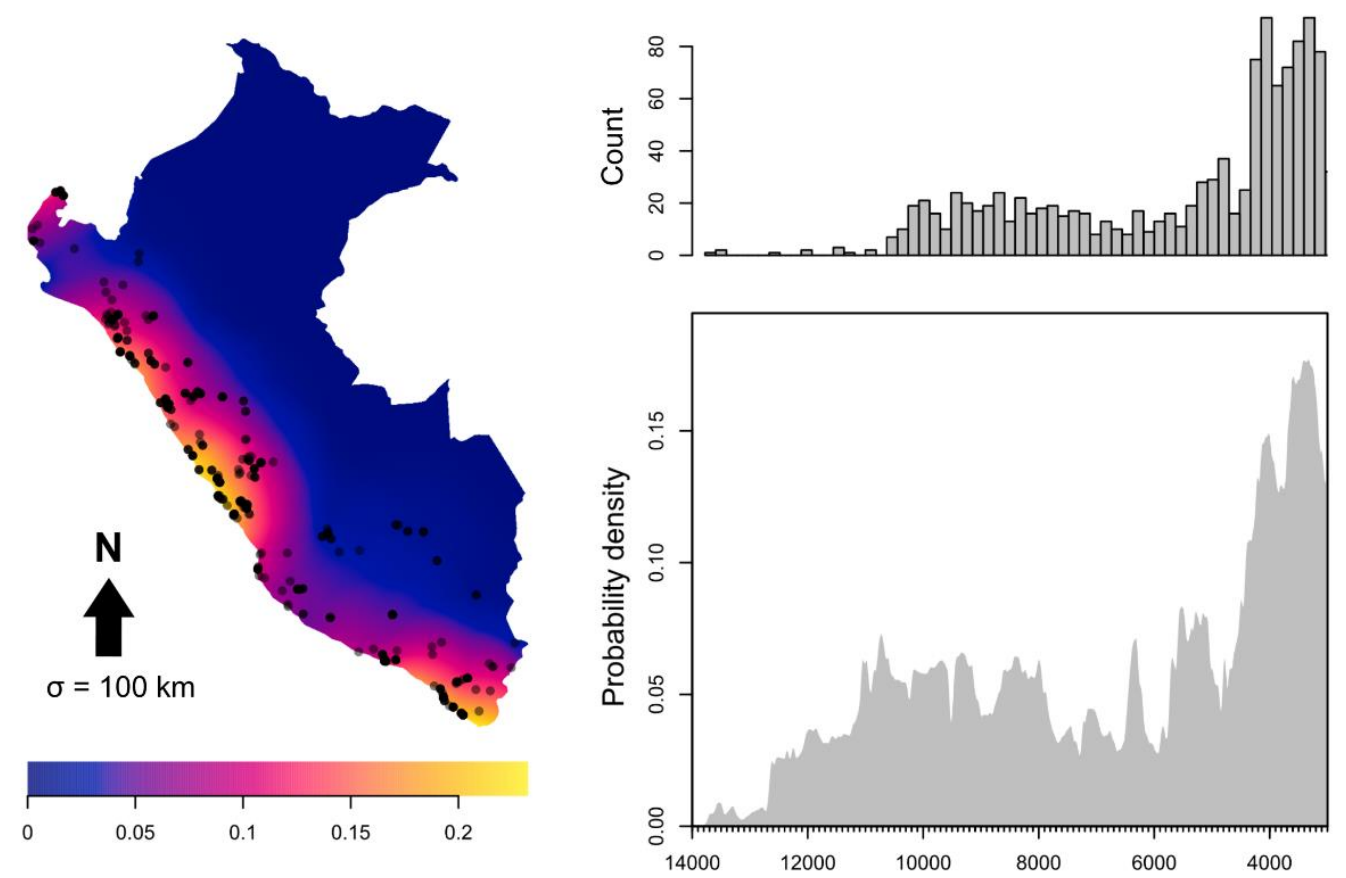

Figure 1: Kernel density estimate (points $/ \mathrm{km}^{2}$ ) and distribution of Peruvian ${ }^{14} \mathrm{C}$ dates $(\mathrm{n}=1180)$ used in this paper (left). Frequency (top right) and non-normalised summed probability distribution (bottom right) of calibrated ${ }^{14} \mathrm{C}$ data in 200-year bins from 14000 to 3000 cal BP.

et al. 2013), as marine resources are a potential source of ancient carbon affecting these dates (Ascough et al. 2005; Bronk Ramsey 2008). Regional marine reservoir offset values ( $\Delta R$ ) from mollusc shells of known age are used to calibrate the marine samples, although considering the highly variable patterns of marine upwelling in the eastern Pacific over time, there is likely some residual errors (Jones et al. 2007). The use of these offsets permits a first order of approximation in this case.

To maintain comparability with the original paper, the same criteria are used to define subsets of the data. That is, Coastal dates are in the range 0-1000 m above sea level, and those above $1500 \mathrm{~m}$ are in the Highland group (Rick 1987, 58). Sampling biases and site destruction likely explain the absence of dates between 1000-1500 m (Rademaker et al. 2013, 42). Here, dates above the $1000 \mathrm{~m}$ contour are all grouped in the Highland category $(n=470)$, while those below are Coastal $(n=780)$. Although a separate analysis of data from the intermediate $1000-1500 \mathrm{~m}$ zone would be ideal, only 37 dates are located here. The few dates obtained $(<10)$ for the preceramic period of Peruvian Amazonia are not employed in the present study.

The method employed for investigating population history through the ${ }^{14} \mathrm{C}$ record follows that of other practitioners performing quantitative analyses on radiometric data. This makes use of the $\mathrm{R}$ statistical environment ( $R$ Core Team 2017) to implement procedures in the package 'rcarbon 1.1.2' (Bevan and Crema 2017). SPDs of calibrated radiocarbon dates are employed as a proxy for past fluctuations in 
relative population in Coastal and Highland Peru. Archaeological analyses of this nature fundamentally rest on the assumption that relatively larger populations introduce more carbon into the material record, resulting in a proportionate amount of ${ }^{14} \mathrm{C}$ determinations produced by archaeologists in the present. Formation processes and preservation bias, taphonomic loss, calibration curve effects, siteand regional-level sampling biases, and varying reporting conventions notwithstanding, this assumption has proven to be robust under many conditions (Rick 1987; Timpson et al. 2014; Weninger et al. 2015; Crema et al. 2016; Goldberg et al. 2016; Edinborough et al. 2017; Bevan et al. 2017; cf. Contreras and Meadows 2014). Summarising the analysis undertaken here, the following procedures are performed on the Peruvian ${ }^{14} \mathrm{C}$ data:

I. Radiocarbon dates are calibrated and aggregated by site into non-overlapping phases for each region over the period $14000-3000{ }^{14} \mathrm{C} \mathrm{BP}$, with an additional 500 years sampled at the extremes of this range to mitigate edge effects. Aggregation is carried out to account for the overrepresentation of very well-dated sites. A sensitivity analysis was undertaken to ascertain the effect of bin sizes (Supplementary Information), which indicates that only very low values (<100 y) have large effects on SPD shape. A bin size of 200 years was employed, well above the median error of 80 years in the dataset.

II. The probability distributions of the calibrated dates are summed over the period. This is performed separately for the coast and highlands over the period of interest, but also using the entire dataset (see Figure 1, bottom right). Following discussion in Weninger et al. (2015) and further discussed in Bevan et al. (2017), the probability distributions are not normalised, reducing the effect of peaks and plateaus in the calibration curves on the shape of the final SPD. The SPDs display a 50-year running average of the probability distribution.

III. The goodness-of-fit of each regional SPD to the inferred population growth trend in Rick (1987) is evaluated, by fitting the calibrated data to a generalised exponential and logistic model for both the Coast and the Highlands. The most parsimonious fitted model for each was selected with the use of an information criterion (Sakamoto et al. 1986). A sample of calendar dates equal to the number of bins are drawn from the fitted model, converted to ${ }^{14} \mathrm{C}$ dates, re-calibrated, and their probability distributions summed. Errors for the re-calibration were generated by sampling with replacement from the empirical ${ }^{14} \mathrm{C}$ errors. Through an additional Monte Carlo procedure of 1000 runs of this protocol, 95\% confidence intervals are derived (Timpson et al. 2014). This procedure omits the marine dates from the analysis, as only a single calibration curve can currently be employed for generating 
confidence envelopes (Bevan and Crema 2017). The two SPDs with marine dates and without marine dates are highly correlated $\left(R^{2}=0.99, p<0.01\right.$, Pearson) and can be expected to capture very similar changes over time in post-calibration probability densities.

IV. Finally and separately, using a permutation test with random assignation of the regional affiliation of all dates (including marine dates), a distribution of simulated SPDs are generated from 1000 Monte Carlo runs, from which 95\% confidence intervals are derived. The empirical SPDs of both regions can are compared against both each other and the pan-regional trend.

The above procedures explore the salient features of the Peruvian radiocarbon record first highlighted in Rick (1987), specifically: i) the extent to which preceramic Coastal demography differs from that of the Highlands, ii) the nature of population trajectories in each broadly-defined setting, and iii) the potential effects of biases (taphonomic deletion, sampling biases, sea level rise), as the use of exponential models has the additional advantage of mimicking time-dependent loss of archaeological sites through these mechanisms (Surovell and Brantingham 2007; Crema et al. 2016). Both sets of tests permit local and global tests of significance to be estimated, and regional population histories to be compared through z-transformation of the empirical and simulated SPDs (Bevan and Crema 2017). Although the Peruvian record suffers from significant selection bias against the highlands (Rademaker et al. 2013), the large quantity of dates from multiple projects likely offsets any bias stemming from any single investigation.

\section{Results}

Comparison of the fitted exponential and logistic null models using Akaike's Information Criterion indicates that for both datasets an exponential model is most parsimonious $\left(\triangle \mathrm{AIC}_{\text {coastal }}=259.98\right.$ and $\left.\Delta \mathrm{AIC}_{\text {Highland }}=327.17\right)$. This model is reported on here, however, the code and data are supplied for replicating both results (Supplementary Information). This result is striking in itself, as Rick (1987) was previously unable to fit his Highland dataset to a model of exponential growth due to the strong dissimilarities between his datasets. It seems plausible that with the advance of time, the quantity of new research (particularly in early periods, see Rademaker et al. 2013) has altered the structure of the Peruvian ${ }^{14} \mathrm{C}$ record substantially, explaining the differences. The results initially suggest that Highland and Coastal communities, for the definitions employed here, experienced relatively similar overall trajectories of growth, decline, and/or stability from initial colonisation until the rise of complex societies in the Late Archaic after circa 3000 cal BP. Nonetheless, both empirical SPDs are significantly different from their respective null models $(p<0.01)$ and necessitate further examination (Figure 2 ). 

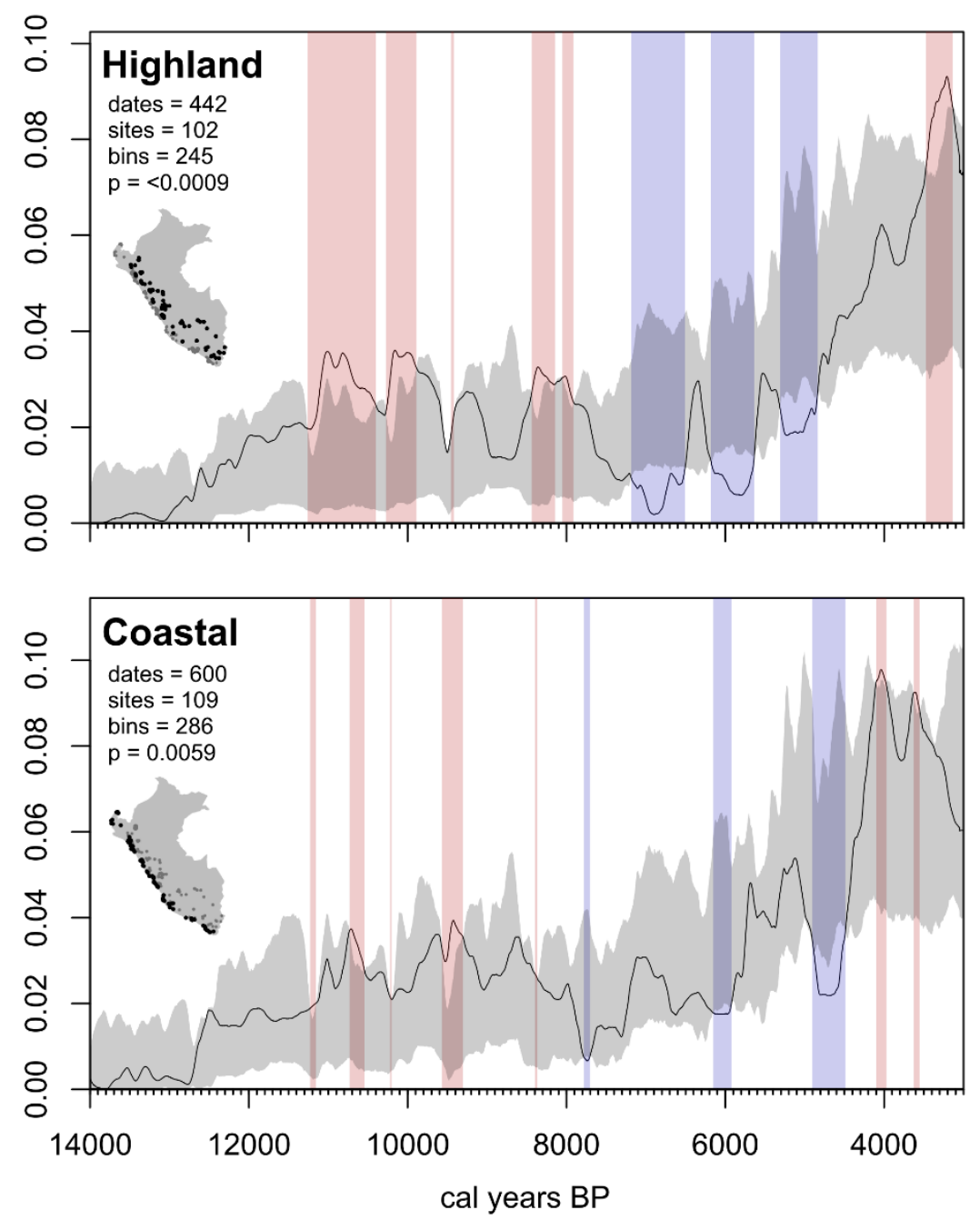

Figure 2: Results of fitting and comparing the Highland (top) and Coastal (bottom) empirical summed probability distributions against exponential models of population growth. Grey envelopes are based on 1000 Monte Carlo runs.

Both the Highland and Coastal SPDs are in line with model expectations for the initial two millennia and experience significant upturns in the millennia surrounding $11000 \mathrm{cal} \mathrm{BP}$, however, this pattern is far more sustained in the Highland dataset, on the order of a millennium. Around $\sim 9500$ cal BP a robust upturn can be seen in the Coastal dataset, but a similar pattern in the Highlands is so slight that it could likely be due to the expected $5 \%$ sampling error (Crema et al. 2016). The same issue applies to the small upturn in the coast just before 10000 cal BP and around $~ 8500$ cal BP. Again, at this point, where the Coastal record barely exceeds the null model, the Highland record shows a more pronounced period of growth beyond model expectations. 
Following this initial phase of steady growth punctuated by periodic upturns (14000 - $8500 \mathrm{cal} B P$ ), both SPDs begin to record crashes resulting from repeated phases of population deflation, albeit with large qualitative differences. Beginning around $\sim 7500 \mathrm{cal} B P$, the Highland ${ }^{14} \mathrm{C}$ record suggests three marked periods of population collapse, bracketing short recoveries lasting in the order of three to four centuries. In contrast, the coast of Peru experiences its first significant downturn somewhat later, around $\sim 7700$ cal BP, followed by a gap of 1500 years until the second downturn $\sim 6100-5900$ cal BP. Another millennium of expected growth occurs before the most sustained period of coastal deflation between $4900-4500$ cal BP. The recovery after the final phase of deflation is so abrupt that by $\sim 4100$ cal BP, the empirical SPD exceeds the opposite edge of the simulation envelope. The post-deflation recovery in the Highland dataset produces a similar pattern by 3500 cal BP.

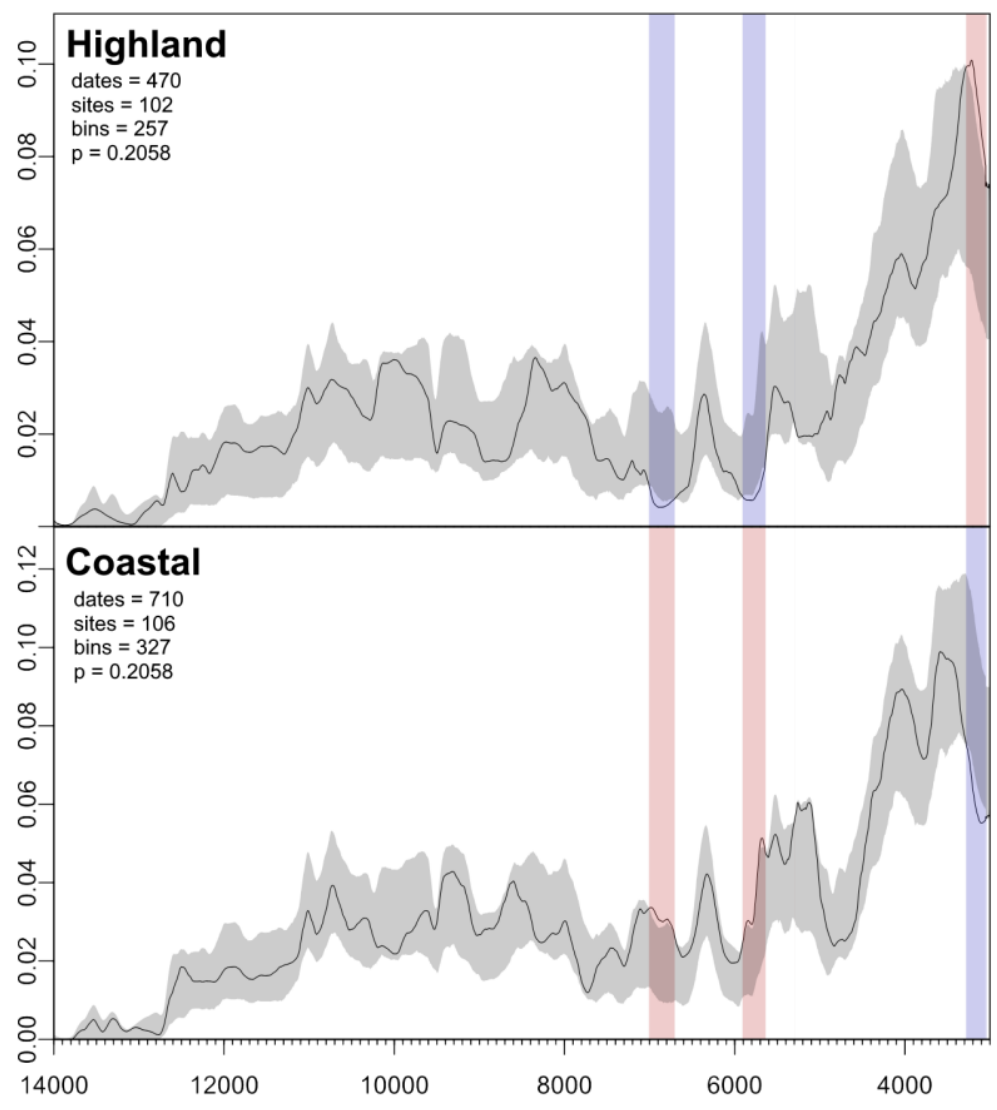

Figure 3: Empirical summed probability distributions of Coastal and Highland radiocarbon dates, compared to a $95 \%$ confidence envelope (grey) derived from the combined dataset. Permutation testing indicates a high degree of correlation between each regional demographic trajectory over time.

These trends reflect numerous qualitative similarities and differences between the two subsets of the Peruvian ${ }^{14} \mathrm{C}$ record. The regional permutation tests, however, provide a more direct comparison between the shapes of the SPDs, and hence the degree to which they may represent divergent 
regional trajectories. The global results of the permutation test suggest that there is no difference between the two sets of dates ( $p>0.05$ in both cases), notwithstanding very brief local divergences just before and after 6000 cal BP. The two crashes observed in the Highland SPD mirror the positions of the first and last periods of population deflation in the model testing (Figure 2, top), during which the Coastal record is experiencing normal growth per model expectations. In contrast, all the preceding phases of significant positive deviation detected in the model testing approach do not appear in the permutation test. This is likely due to the patterns being a) largely concurrent, meaning no difference on a global level can be registered between the two SPDs and, $b$ ) in the cases where there are notable differences, they not sustained for longer periods of time. Nonetheless, a Highland expansion close to 3000 cal BP is plausible (Figure 3, top), yet could be due to unaccounted-for edge effects, while the reality of a Coastal bust (Figure 3, bottom) appears unlikely given the previous results (see Figure 2). Overall, the statistical testing and qualitative assessment of the SPDs and envelopes indicate little divergence from the null hypothesis of no difference between Coastal and Highland demographic trajectories (cf. Rick 1987). I now consider the implications of these findings.

\section{Discussion}

This section evaluates the results of this study against past approaches to indigenous South American demography that employ archaeological SPDs of calibrated ${ }^{14} \mathrm{C}$ dates. Following precedent (Shennan et al. 2013; Crema et al. 2016), the simulation-based approach employed here permits statistical confidence in the results to be estimated both globally and locally. First, I tackle the regional population histories of the Pacific coast and the highland interior of Peru comparatively. Second, I compare the long-term demographic trends revealed by the SPDs against extant knowledge on transitions in society and environment from the Terminal Pleistocene to the Late Holocene. Finally, I address the implications of this in the context of broader cultural trends and technological innovations across Peru from colonisation to the end of the preceramic period.

The permutation tests reveal robust and consistent cross-regional patterns that permit population trends to be discussed comparatively. Contrary to previous analyses of the Peruvian ${ }^{14} \mathrm{C}$ record, remarkable consistency between the coast and the highlands can be observed from 14000 until 3000 cal BP (Figure 3). Nonetheless, the permutation test SPDs fall outside the $95 \%$ confidence intervals for brief periods during the middle Holocene, at approximately 7000-6700 cal BP and 5900-5600 cal BP. These intervals provide the strongest evidence for local depopulation/expansion events at specific points in time. A later divergence between the two regions also occurs towards the very end of the Archaic period, however, without additional data extending into the later Holocene (in cultural- 
historical terms, the Initial Period onwards), it remains challenging to ascertain how consistent this pattern is beyond the period investigated here.

The greatest differences, as noted, take place in two defined intervals within the Middle Holocene chron, a critical phase of transition in terms of both climate and culture in the study region (Sandweiss et al. 1999; Keefer et al. 2003; Gayo et al. 2015). Nonetheless, it is possible that the regional divisions implemented here are masking potentially more profound variation between different sets of subregions. Indeed, this was raised in the original study (Rick 1987, 68), particularly as concerns another distinctive Andean biome: the puna. Human societies face a significantly different set of challenges to the successful colonisation of this environment, a montane region of grasslands that begins approximately 3200 metres above sea level, compared to both the coast and the lower reaches of the highlands. These include hypoxic conditions requiring progressive adaptation, as well as patchy water resources (Aldenderfer 2006; Núñez et al. 2013; Rademaker et al. 2014; Yacobaccio et al. 2017). Furthermore, as most high Andean precipitation is derived from the South American Summer Monsoon (and ultimately, the Atlantic Ocean) system, large parts of the puna are particularly vulnerable to aridification caused by a weakened monsoon (Núñez et al. 2002; 2013). A different set of population dynamics could be expected given these constraints and conditions over the range of the Holocene, which in turn ought to be reflected in the ${ }^{14} \mathrm{C}$ record.

To test this, I repeated the permutation test with three different subsets. Puna dates are inclusively defined as those from sites with elevations $>3200 \mathrm{~m}$, based on the SRTM elevation model v4.1 (Jarvis et al. 2008). The range of Coastal sites is reduced to 0-500 m elevation, while a third, new Intermediate group covers the interval 500-3200 m. Excepting the quantity of dates per group (Coastal $=599$, Intermediate $=343$, Puna, $n=238$ ), all other parameters described above were held the same. This version of the permutation test (Figure 4) provides an alternative view of disaggregated regional population trends to the prior comparison of desert coast and highlands.

This second permutation test shows significant deviations from the null hypothesis in the Puna and Intermediate datasets, and a global p-value of just above the significance threshold for the Coastal group. Population expansion is still evident in the desert coast around $\sim 6000 \mathrm{cal} B P$, however, here it is joined by population deflation around $\sim 1000 \mathrm{cal} B P$ that is also observable in the Puna to a much greater degree. It ought to be cautioned that this very early Puna gap may be due to a comparative lack of research in extreme high-altitude environments, or perhaps, its hostility to initial colonisation efforts (Aldenderfer 2006). In contrast, the Intermediate zone shows a long, sustained period above 
the pan-regional trend between approximately $12800-10800 \mathrm{cal} \mathrm{BP}$, and again in the centuries around 10000 cal BP. Mid-Holocene population crashes that appear in the Highland dataset appear to have been shifted towards the late Holocene transition (4200 cal BP) in the Intermediate dataset. At the same time, the Highland deflation around $\sim 7000$ cal BP (lasting some four centuries) is approximately concurrent with a similar pattern observed in the Puna in this test. By comparison, Coastal population levels appear to have thrived over these same intervals, although joined by the Puna around $\sim 5000 \mathrm{cal}$ BP while the Intermediate zone was experiencing downturns. Overall, the picture presented by these three subregions of the Peruvian ${ }^{14} \mathrm{C}$ data could suggest a degree of
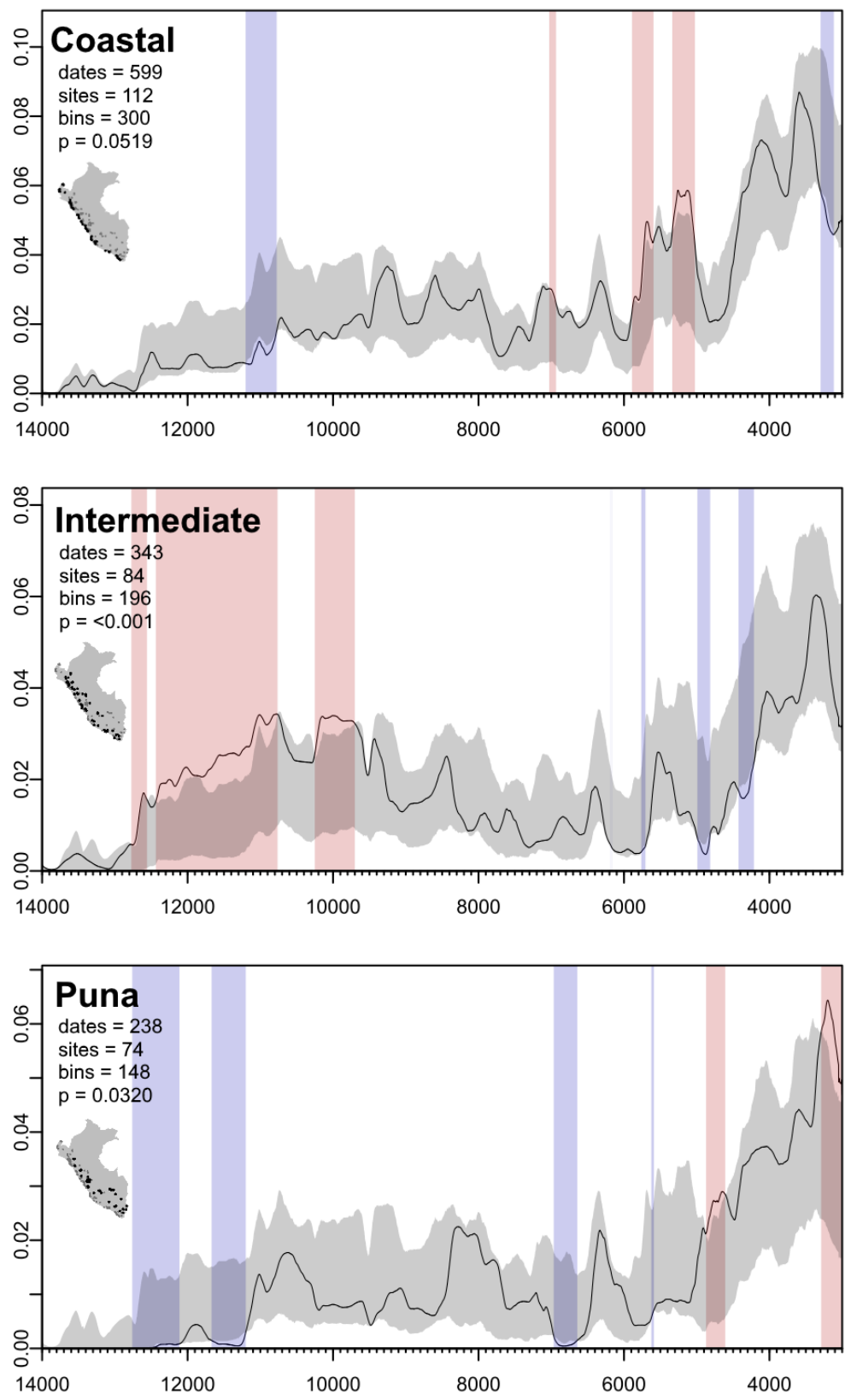

Figure 4: Regional permutation test between Puna ${ }^{14} \mathrm{C}$ data $(>3200 \mathrm{~m})$, and Coastal and Intermediate zone data. 
teleconnectivity between the demographic trends of different regions, however, they are also out of phase with one another important ways.

Recent studies have marshalled population genetics, geoarchaeology, and importantly, climate archives to contextualise the wealth of data on pre-Columbian demographic processes (Keefer et al. 2003; Dillehay and Kolata et al. 2004; Fehren-Schmitz et al. 2014; Perez et al. 2017). Figure 5a-c presents three palaeoclimatic archives for the Holocene that are of especial importance to contextualising millennial-scale demographic patterns illustrated by the model and permutation testing. Together they approximate the source and availability of water for the study regions over time (Pacific versus Atlantic), as ENSO introduces precipitation to the desert coast, while the SASM waters higher elevations. First, the Nevado Sajama ice core (Bolivia) records the quantity of dust particles over time as an index of aridity at altitude in the Andes (Thompson et al. 1998; 2000). Second, alkenone measurements from a series of marine sediment cores across a transect of water depths, and using the $\mathrm{U}^{\mathrm{K}^{\prime}}{ }_{37}$ calibration, provides an estimate of sea surface temperature (SST) variation in Celsius $\left({ }^{\circ} \mathrm{C}\right.$ ) along the Peruvian margin (Bova et al. 2015). This also indexes the degree of marine upwelling and hence the availability of different fish stocks (Chavez et al. 2003; Sandweiss et al. 2004). Third, and complementary to this, the 106KL marine sediment core records the concentration and accumulation rate (flux) of terrestrial lithic input from a continental shelf site (Rein et al. 2005). This provides a proxy for the frequency and intensity of ENSO events, as a driver of coastal flooding, highland aridity, sea temperature inversions, and resulting reconfigurations of coastal aquatic ecosystems (Moy et al. 2002; Keefer et al. 2003; Chavez et al. 2003; Sandweiss et al. 2004; Williams et al. 2008). Both concentration and flux are rendered as a percentage of the maximum recorded value in the core and must be interpreted together, as very low flux rates for the mid-Holocene could in part be due to erosional processes as well as a suppressed ENSO (Rein et al. 2005).

Comparing the three regional SPDs (Figure 5d) with 50-year running averages of these data suggests some likely correlations between demography and Holocene climate variability. The spike in highland aridity at $\sim 7000$ cal BP, likely caused by a weakened SASM and possible ENSO activity at this point in time (Baker et al. 2001; Rein et al. 2005), precedes a significant crash in puna population. Later, more severe phases of aridity, corresponding to the Holocene lowstand of Lake Titicaca, (Baker et al. 2001), align closely with the crashes identified in the intermediate zone. These patterns largely agree with weak mid-Holocene anthropic signals that have been observed contemporaneously at similar elevations in the even more arid South-Central Andes (Núñez et al. 2013; Muscio and López 2016). 

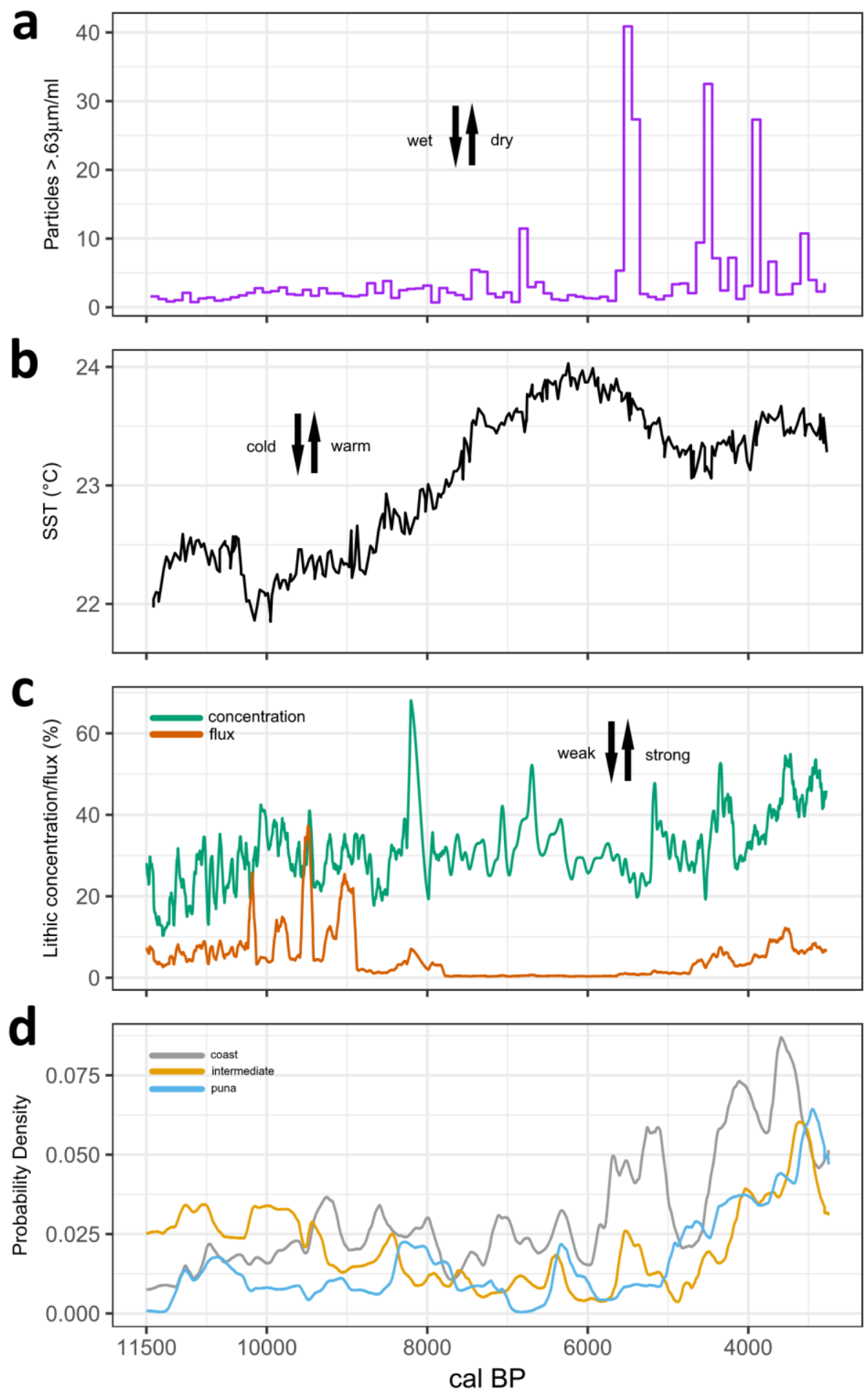

Figure 5: Proxies for regional palaeoclimate since the onset of the Holocene. a) Sajama (Bolivia) ice core particle counts (Thompson et al. 1998). b) Alkenonederived SST estimates for the eastern Pacific (Bova et al. 2015). c) Lithic input concentration (green) and relative accumulation rate (red) from the $106 \mathrm{KL}$ core (Rein et al. 2005). d) Summed probability distributions for the Coastal (grey), Intermediate (gold), and Puna zones (blue).

A depression in lithic input is coeval with a phase of warmer SST during the mid-Holocene (8200 $4200 \mathrm{cal}$ BP), and indicates a weakened or absent ENSO phenomenon during this chron. Coastal populations appear to have benefitted from this configuration (see Figure 4, top; see also Sandweiss 
2003). Interestingly, the very strong phase of input around 8200 cal BP, which has possible geoarchaeological correlates with catastrophic flooding and evidence of site abandonment (Fontugne et al. 1999; Keefer et al. 2003) is associated to concurrent long-term downturns in all three SPDs, which nonetheless fall within the range of variation expected by the envelope. Similarly, the reemergence of a strong ENSO with the commencement of the later Holocene (Moy et al. 2002) appears to have the largest impact on the Coastal SPD, displaying a sharp, albeit non-significant, downturn. Despite this, and the two closely-associated significant downturns in the Intermediate area, rapid recoveries are evident, suggesting a degree of resilience to abrupt climatic events by this time. A stronger than expected anthropic signal in the Peruvian puna at $\sim 4900$ cal BP, close to phases of peak aridity at altitude, also suggests that populations occupying highly distinct niches were beginning to adapt successfully to the challenges presented by a changing Holocene climate (Sandweiss 2003; Núñez et al. 2013; Marsh 2015).

While demography does not always closely track climatic variability over the timespan in question, this should not be taken as evidence that there was a total absence of impact on the preceramic societies of Peru. Site abandonment or destruction was likely preceded by catastrophic flooding resulting from shifts in the ENSO regime (Fontugne et al. 1999; Sandweiss 2003), while also contributing to the deletion of mid-elevation sites (Keefer et al. 2003; Rademaker et al. 2013). Variability in access, adoption, and success rates of subsistence, social, and technological innovations also likely explains some of the out-of-phase demographic recoveries observed in the SPDs. The precocious adoption of a diversified resource base in the early Holocene likely afforded an initial measure of protection against sustained periods of climatic instability and aridity, for example at the onset of the middle Holocene. Only a few millennia after initial colonisation, early Holocene foraging societies in both the highlands and coast began to incorporate cultivated plants into their subsistence systems. The record of early plant cultivation reveals broad-spectrum use of domesticated crops in Peru, including squash, peanut, a variety of tubers, and beans, which complemented marine, aquatic, and terrestrial resource bases (Piperno and Dillehay 2008; Pearsall 2008; Piperno 2011). In parallel, these horticultural communities were experimenting with new forms of social organisation (Sandweiss et al. 1999). By the end of the preceramic period, rooted in processes observed in the midHolocene record of Peru, politically and economically integrated hierarchical polities are an archaeological fact (Stothert et al. 2003; Dillehay et al. 2003; Pozorski and Pozorski 2008; 2017). In turn, this trajectory may have increased the reliance of horticultural and high-altitude agro-pastoralist societies on anthropic niches to reinforce their pre-existing and adaptive strategies (Brooks 2006; Boivin et al. 2016; Marsh 2016; Blockley et al. 2018). 
In this, the pre-Columbian record of Peru may differ markedly from, for example Northern Europe, which experiences no implicit correlation between increased technological and subsistence sophistication, and societal resilience (see Bevan et al. 2017). Nonetheless, highly anomalous climatic events did have cascading effects, albeit frequently offset in time from the SPDs, and responses to climate change likely varied substantially on a local scale (see Fontugne et al. 1999; Keefer et al. 2003; Sandweiss 2003), particularly as ENSO-driven rainfall patterns can have a highly heterogeneous spatial distribution (Moy et al. 2002; Rein et al. 2005). This study has attempted to address questions at a scale commensurate with Rick (1987); future research aiming to trace the evolution of concurrent adaptive strategies in coastal, highland, and puna biomes by pre-Columbian societies will help to reveal the requisite conditions for the emergence of stratified polities. The results of this study underline that robust statistical frameworks should underpin comparative investigations, ideally using simulation techniques.

\section{Conclusions}

Except for a relatively small number of deviations on the centennial scale, the Peruvian ${ }^{14} \mathrm{C}$ record for the desert coast, highlands, and puna form part of a single pan-regional demographic trend from the end of the Pleistocene until the late Holocene. Furthermore, these trajectories are only consistent with major climatic shifts in some circumstances. The strongest evidence for deleterious impact on indigenous societies can be found at major points of transition, such as the end of the Younger Dryas in the Coastal region, the late Holocene transition in the intermediate zone, and at peak mid-Holocene aridity in the puna. Nonetheless, population recovery is rapid and precedes alleged "ameliorations" in climate, particularly approaching the late Holocene (4200 cal BP onwards). This phase of transition, where ENSO activity and aridity peak, appear to have affected Intermediate populations more profoundly than those on the desert coast. Although population in terms of absolute numbers likely differed between the zones in question, their trajectories and sensitivity (or lack thereof) to climate change appear to be coeval in many cases. As a measure of relative population, SPDs provide useful insight into pan-regional dynamics over time. The results of the statistical tests argue against purely inductive pattern recognition for assessing population history using archaeological ${ }^{14} \mathrm{C}$ data (see Rick 1987; Araujo et al. 2005; Grosjean et al. 2007; Neme and Gil 2009; Mendéz et al. 2015; Gayo et al. 2015; Barberena et al. 2017), particularly where climate change is invoked as a direct causal mechanism (Núñez et al. 2002; Yacobaccio et al. 2017). Explicit comparisons between theoretical models of population growth and empirical radiocarbon records are necessary, here as in previous work (Rick 1987). 
Finally, it is worth reflecting on current methods of significance testing in the analysis of archaeological SPDs (see Bevan and Crema 2017). Future investigations and extensions of this method might pay more attention to the rate of change of the empirical SPD slope, meaning the growth rate of a theoretical population, rather than its deviation from a simulation envelope. Observe, for example, the slope of the SPD in Figure 4 (top) after the final positive deviation at 6000 cal BP, discussed above. This drop, while non-significant, is much greater in amplitude than a concurrent (significant) event in the Intermediate subset. Methods for quantifying statistical deviation from the average gradient of an SPD might provide another way to study these oscillations of population levels around the mean trend (see also Edinborough et al. 2017), as large troughs may be suggestive of a large reduction in relative population levels that, nonetheless, do not attain statistical significance given the way in which the method current frames its null hypothesis.

In summary, summed probability distributions of calibrated radiocarbon dates have provided a proxy for relative changes in pre-Columbian demography throughout the preceramic period of Peru. With the benefit of additional data and methodological advances, this produced some striking differences from prior findings in the study area (see Rick 1987), underscoring the value of marshalling these resources for the re-examination of such venerable studies (Huggett 2018). Broader-scale analyses of archaeological radiocarbon data can produce novel insights into a neglected area of research in the pre-Columbian Americas. The integration of established databases (for example, Williams et al. 2008; Gayo et al. 2015; Goldberg et al. 2016; Barberena et al 2017) into broader comparative frameworks, combined with high-resolution local palaeoclimatic and palaeoecological indices, will be instrumental in this regard. As the scale and legacy of environmental impact are necessarily linked to demography, precisely measuring the effects of prehistoric societies on the biosphere will increasingly becoming a concern in the human sciences.

\section{Acknowledgements}

The concept for this paper was precipitated by discussions at the Cross-Disciplinary Approaches to Prehistoric Demography (CROSSDEM) workshop, hosted at the Institut Català de Paleoecologia Humana i Evolució Social (Tarragona, Spain) in February 2018. Fabio Silva is especially thanked for testing part of my code, elements of which were adapted from work by Andrew Bevan, who is also thanked. Benjamin Davies and three anonymous reviewers provided useful and welcome commentary on earlier drafts. This research was generously supported by a Visiting Fellowship at the Sainsbury 
Research Unit, Sainsbury Centre for Visual Arts, University of East Anglia during early 2018. Any errors are my own.

\section{References}

Aldenderfer, A. 1999. The Pleistocene/Holocene transition in Peru and its effects upon human use of the landscape. Quaternary International 53-54: 11-19. DOI: 10.1016/S1040-6182(98)00004-4

Aldenderfer, A. 2006. Modelling plateau peoples: the early human use of the world's high plateaux. World Archaeology 38: 357-370. DOI: 10.1080/00438240600813285

Araujo. A. et al. 2005. Human occupation and paleoenvironments in South America: expanding the notion of an "Archaic Gap". Rev. do Museu de Arqueologia e Etnologia 15-16: 3-35. DOI: 10.11606/issn.2448-1750.revmae.2006.89707

Ascough, P. G. Cook, and A. Dugmore. 2005. Methodological approaches to determining the marine radiocarbon reservoir effect. Progress in Physical Geography: Earth and Environment 29: 532547. DOI: $10.1191 / 0309133305 p p 461$ ra

Barberena, R. C. Mendéz, M.E. de Porras. 2017. Zooming out from archaeological discontinuities: The meaning of mid-Holocene temporal troughs in South American deserts. Journal of Anthropological Archaeology 46: 68-81. DOI: 10.1016/i.jaa.2016.07.003

Baker, P.A. et al. 2001. The History of South American Tropical Precipitation for the Past 25,000 Years. Science 291: 640-643.

Bevan, A. and E.R. Crema. 2017 rcarbon v1.0.0 : Methods for calibrating and analysing radiocarbon dates URL: https://CRAN.R-project.org/package=rcarbon

Bevan, A. et al. 2017. Holocene fluctuations in human population demonstrate repeated links to food production and climate. PNAS 114: E10524-E10531. DOI: 10.1073/pnas.1709190114

Blockley, S. et al. 2018. The resilience of postglacial hunter-gatherers to abrupt climate change. Nature Ecology and Evolution. DOI: doi.org/10.1038/s41559-018-0508-4 
Bronk Ramsey, C. 2008. Radiocarbon dating: revolutions in understanding. Archaeometry 50: 249-275. DOI: 10.1111/i.1475-4754.2008.00394.x

Bronk Ramsey, C. 2017. Methods for Summarizing Radiocarbon Datasets. Radiocarbon 59: 1809-1833. DOI: $10.1017 / R D C .2017 .108$

Boivin, N.L. et al. 2016. Ecological consequences of human niche construction: Examining long-term anthropogenic shaping of global species distributions. PNAS 113: 6388-6396. DOI: $\underline{10.1073 / \text { pnas. } 1525200113}$

Bova, S.C. et al. 2015. Links between eastern equatorial Pacific stratification and atmospheric $\mathrm{CO}_{2}$ rise during the last deglaciation. Paleoceanography 30: 1407-1424. DOI: 10.1002/2015PA002816

Chavez, F.P. et al. 2003. From anchovies to sardines and back: multidecadal change in the Pacific Ocean. Science 299: 217-221. DOI: 10.1126/science.1075880

Crema, E.R., J. Habu, K. Kobayashi and M. Madella. 2016. Summed Probability Distribution of ${ }^{14} \mathrm{C}$ Dates Suggests Regional Divergences in the Population Dynamics of the Jomon Period in Eastern Japan. PLOS ONE 11: e0154809. DOI: 10.1371/journal.pone.0154809

Crema, E.R., A. Bevan, S. Shennan. 2017. Spatio-temporal approaches to archaeological radiocarbon dates. Journal of Archaeological Science 87: 1-9. DOI: 10.1016/i.jas.2017.09.007

Contreras, D.A. and J. Meadows. 2014. Summed radiocarbon calibrations as a population proxy: a critical evaluation using a realistic simulation approach. Journal of Archaeological Science 52: 591-608. DOI: 10.1016/i.jas.2014.05.030

Dillehay, T.D., et al. 2003. Localization and possible social aggregation in the Late Pleistocene and Early Holocene on the north coast of Perú. Quaternary International 109-110: 3-11. DOI: $\underline{10.1016 / S 1040-6182(02) 00198-2}$

Dillehay, T.D. and A.L. Kolata. 2004. Long-term human response to uncertain environmental conditions in the Andes. PNAS 101: 4325-4330. DOI: 10.1073/pnas.0400538101 
Dillehay, T.D. et al. 2015. New Archaeological Evidence for an Early Human Presence at Monte Verde, Chile. PLOS ONE 10: e0145471. DOI: 10.1371/journal.pone.0141923

Edinborough, K. et al. 2017. Radiocarbon test for demographic events in written and oral history. PNAS 114: 12436-12441. DOI: 10.1073/pnas.1713012114

Fehren-Schmitz, L. et al. 2014. Climate change underlies global demographic, genetic, and cultural transitions in pre-Columbian southern Peru. PNAS 111: 9443-9448. DOI: $\underline{10.1073 / \text { pnas. } 1403466111}$

Fontugne, M. et al. 1999. El Niño variability in the coastal desert of southern Peru during the MidHolocene. Quaternary Research 52: 171-179.

Gamble, C. et al. 2005. The Archaeological and Genetic Foundations of the European Population during the Late Glacial: Implications for 'Agricultural Thinking'. Cambridge Archaeological Journal 15: 193-223. DOI: 10.1017/S0959774305000107

Gayo, E.M., C. Latorre, and C.M. Santoro. 2015. Timing of occupation and regional settlement patterns revealed by time-series analyses of an archaeological radiocarbon database for the SouthCentral Andes $\left(16^{\circ}-25^{\circ} \mathrm{S}\right)$. Quaternary International 356: 4-14. DOI: $\underline{10.1016 / \text { i.quaint.2014.09.076 }}$

Goldberg, A., A.M. Mychajiliw and E.A. Hadley. 2016. Post-invasion demography of prehistoric humans in South America Nature 532: 232-235. DOI: 10.1038/nature17176.

Grosjean, M. et al. 2007. Mid-Holocene climate and cultural change in the South-Central Andes. In: Anderson, D.G., K.A. Maasch, and D.H. Sandweiss. Climate Change and Cultural Dynamics: A Global Perspective on Mid-Holocene Transitions. Cambridge, MA: Academic Press. 51-115.

Haas, J. and W. Creamer. 2006. Crucible of Andean Civilization: The Peruvian Coast from 3000 to 1800 BC. Current Anthropology 47: 745-775. DOI: 10.1086/506281

Haas, J., W. Creamer and A. Ruiz. 2004. Dating the Late Archaic occupation of the Norte Chico region in Peru. Nature 432: 1020-1023. DOI: 10.1038/nature03146 
Hogg, A.G. et al. 2013. SHCal13 Southern Hemisphere calibration, 0-50,000 years cal BP. Radiocarbon 55: 1889-1903. DOI: $10.2458 / a z u$ is rc.55.16783

Huggett, J. 2018. Reuse remix recycle: repurposing archaeological digital data. Advances in Archaeological Practice 6: 93-104. DOI: 10.1017/aap.2018.1)

Jarvis, A. et al. 2008. Hole-filled SRTM for the Globe Version 4. Available: CGIAR-CSI SRTM 90m Database (http://srtm.csi.cgiar.org).

Jones, K.B. et al. 2007. Seasonal variations in Peruvian marine reservoir age from pre-bomb Argopecten purpuratus shell carbonate. Radiocarbon 49: 877-888. DOI: $\underline{10.1017 / S 0033822200042740}$

Keefer, D.K. et al. 2003. A 38 000-year record of floods and debris flows in the llo region of southern Peru and its relation to El Niño events and great earthquakes. Palaeogeography, Palaeoclimatology, Palaeoecology 194: 41-77. DOI: 10.1016/S0031-0182(03)00271-2

Marsh, E.J. 2015. The emergence of agropastoralism: Accelerated ecocultural change on the Andean altiplano, $\sim 3540-3120$ cal BP. Environmental Archaeology 20: 13-29. DOI: $\underline{10.1179 / 1749631414 Y .0000000036}$

Marsh, E.J. 2016. The disappearing desert and the emergence of agropastoralism: An adaptive cycle of rapid change in the mid-Holocene Lake Titicaca Basin (Peru-Bolivia). Quaternary International 422: 123-134. DOI: 10.1016/i.quaint.2015.12.081

Mendéz, C. et al. 2015. Mid Holocene radiocarbon ages in the Subtropical Andes ( $\left.29^{\circ}-35^{\circ} \mathrm{S}\right)$, climatic change and implications for human space organization. Quaternary International 356: 15-26. DOI: $10.1016 /$ i.quaint.2014.06.059

Moseley, M.E. 1992. Maritime Foundations and Multilinear Evolution: Retrospect and Prospect. Andean Past 3: 5-42. 
Moy, C.M. et al. 2002. Variability of El Niño/Southern Oscillation activity at millennial timescales during the Holocene epoch. Nature 420: 162-165. DOI: 10.1038/nature01194

Muscio, H.J. and López, G.E.J. 2016. Radiocarbon dates and anthropogenic signal in the South-Central Andes (12,500-600 cal. years BP). Journal of Archaeological Science 65: 93-102. DOI: $\underline{10.1016 / j . j a s .2015 .11 .007}$

Neme, G. and Gil, A., 2009. Human occupation and increasing mid-Holocene aridity: southern Andean perspectives. Current Anthropology 50: 149-163. DOI: 10.1086/596199

Núñez, L., Grosjean, M. and Cartajena, I. 2002. Human occupations and climate change in the Puna de Atacama, Chile. Science 298: 821-824. DOI: 10.1126/science.1076449

Núñez, L., Cartajena, I. and Grosjean, M. 2013 Archaeological silence and ecorefuges: Arid events in the Puna of Atacama during the Middle Holocene. Quaternary International 307: 5-13. DOI: $\underline{10.1016 / \text { i.quaint.2013.04.028 }}$

Palmisano, A., A. Bevan and S. Shennan. 2017. Comparing archaeological proxies for long-term population patterns: An example from central Italy. Journal of Archaeological Science 87: 59-72. DOI: 10.1016/i.jas.2017.10.001

Pearsall, D. 2008. Plant Domestication and the Shift to Agriculture in the Andes. In: Silverman, H. \& W.H. Isbell. (Eds.), Handbook of South American Archaeology London: Springer. 105-120.

Perez, S.I., M.B. Postillone and D. Rindel. 2017. Domestication and human demographic history in South America. American Journal of Physical Anthropology. 163: 44-52. DOI: 10.1002/ajpa.23176

Piperno, D.R. 2011. The Origins of Plant Cultivation and Domestication in the New World Tropics. Current Anthropology 52: 453-470. DOI: 10.1086/659998

Piperno, D.R. and T.D. Dillehay. 2008. Starch grains on human teeth reveal early broad crop diet in northern Peru PNAS 105: 19622-19627. DOI: 10.1073/pnas.0808752105 
Pozorski, S. and T. Pozorski. 2008. Early Cultural Complexity on the Coast of Peru. In: Silverman, H. \& W.H. Isbell. (Eds.), Handbook of South American Archaeology. London: Springer. 607-633.

Pozorski, T. and S. Pozorski. 2017. Early Complex Society on the North and Central Peruvian Coast: New Archaeological Discoveries and New Insights. Journal of Archaeological Research DOI: $\underline{10.1007 / s 10814-017-9113-3}$

Quilter, J. and T. Stocker. 1983. Subsistence Economies and the Origins of Andean Complex Societies. American Anthropologist 85: 545-562. DOI: 10.1525/aa.1983.85.3.02a00030

R Core Team. 2017. R: A Language and Environment for Statistical Computing (version 3.4.2). $\mathrm{R}$ Foundation for Statistical Computing. Vienna, Austria.

Rademaker, K., G.R.M. Bromley, D.H. Sandweiss. 2013. Peru archaeological radiocarbon database, 13,000-7000 ${ }^{14}$ C B.P. Quaternary International 301: 34-45. DOI: 10.1016/i.quaint.2012.08.2052

Rademaker, K. et al. 2014. Paleoindian settlement of the high-altitude Peruvian Andes. Science 346: 466-469. DOI: $10.1126 /$ science. 1258260

Reimer, P.J. et al. 2013. IntCal13 and Marine13 radiocarbon age calibration curves $0-50,000$ years cal BP. Radiocarbon 55: 1869-1887. DOI: 10.2458/azu is rc.55.16947

Rein, B. et al. 2005. El Niño variability off Peru during the last 20,000 years Paleoceanography 20: PA4003. DOI: 10.1029/2004PA001099

Rick, J.W. 1987. Dates as Data: An Examination of the Peruvian Preceramic Radiocarbon Record. American Antiquity 52: 53-77. DOI: 10.2307/281060

Sakamoto, Y., M. Ishiguro and G. Kitagawa. 1986. Akaike Information Criterion Statistics. Tokyo: KTK Scientific Publishers.

Sandweiss, D.H., K.A. Maasch and D.G. Anderson. 1999. Transitions in the Mid-Holocene. Science 283: 499-500. DOI: $10.1126 /$ science.283.5401.499 
Sandweiss, D.H. 2003. Terminal Pleistocene through Mid-Holocene archaeological sites as paleoclimatic archives for the Peruvian coast. Palaeogeography, Palaeoclimatology, Palaeoecology 194: 23-40. DOI: 10.1016/S0031-0182(03)00270-0

Sandweiss, D.H. et al. 2004. Geoarchaeological evidence for multidecadal natural climatic variability and ancient Peruvian fisheries. Quaternary Research 61: 330-334. DOI: $\underline{10.1016 / \text { j.yqres.2004.02.008 }}$

Sandweiss, D.H. et al. 2007. Mid-Holocene climate and culture change in coastal Peru. In: Anderson, D.G., K.A. Maasch, and D.H. Sandweiss. Climate Change and Cultural Dynamics: A Global Perspective on Mid-Holocene Transitions. Cambridge, MA: Academic Press. 25-50.

Shady Solís, R., J. Haas and W. Creamer. 2001. Dating Caral, a Preceramic Site in the Supe Valley on the Central Coast of Peru. Science 292: 723-726. DOI: 10.1126/science.1059519

Shennan, S. et al. 2013. Regional population collapse followed initial agriculture booms in midHolocene Europe. Nature Communications 4: 2486. DOI: 10.1038/ncomms3486

Stothert, K.E., D.R. Piperno, and T.C. Andres. 2003. Terminal Pleistocene/Early Holocene human adaptation in coastal Ecuador: the Las Vegas evidence. Quaternary International 109-110: 2343. DOI: 10.1016/S1040-6182(02)00200-8

Surovell, T.A. and P.J. Brantingham. 2007. A note on the use of temporal frequency distributions in studies of prehistoric demography. Journal of Archaeological Science 34: 1868-1877. DOI: 10.1016/j.jas.2007.01.003

Timpson, A. et al. 2014. Reconstructing regional population fluctuations in the European Neolithic using radiocarbon dates: a new case-study using an improved method. Journal of Archaeological Science 52: 549-577. DOI: 10.1016/j.jas.2014.08.011

Thompson, L.G. et al. 1998. A 25,000 year tropical climate history from Bolivian ice cores. Science 282: 1858-1864. DOI: $10.1126 /$ science.282.5395.1858 
Thompson, L.G., E. Mosley-Thompson, and K.A. Henderson. 2000. Ice-core palaeoclimate records in tropical South America since the Last Glacial Maximum. Journal of Quaternary Science 15: 377394. DOI: 10.1002/1099-1417(200005)15:4<377::AID-JQS542>3.0.CO;2-L

Turney, C.S. and H. Brown. 2007. Catastrophic early Holocene sea level rise, human migration and the Neolithic transition in Europe. Quaternary Science Reviews 26: 2036-2041. DOI: $\underline{10.1016 / \text { j.quascirev.2007.07.003 }}$

Weninger, B., et al. 2015. Quantum theory of radiocarbon calibration. World Archaeology 47: 543566. DOI: $10.1080 / 00438243.2015 .1064022$

Williams, A.N. et al. 2008. The impact of ENSO in the Atacama Desert and Australian Arid Zone: exploratory time-series analysis of archaeological records. Chungara, Revista de Antropología Chilena 40: 245-259. DOI: 10.4067/S0717-73562008000300003.

Williams, A.N. 2012. The use of summed radiocarbon probability distributions in archaeology: a review of methods. Journal of Archaeological Science 39: 578-589. DOI: 10.1016/i.jas.2011.07.014

Yacobaccio, H.D., M.R. Morales and R. Hoguin. 2017. Habitats of ancient hunter-gatherers in the Puna: Resilience and discontinuities during the Holocene. Journal of Anthropological Archaeology 46: 92-100. DOI: 10.1016/i.jaa.2016.08.004 